\title{
Apropiación patrimonial en contextos mineros de Andalucía ${ }^{1}$
}

\author{
MACARENA HERNÁNDEZ RAMÍREZ y \\ ESTEBAN RUIZ BALLESTEROS \\ Departamento de Ciencias Sociales \\ Universidad Pablo de Olavide. Sevilla
}

\section{RESUMEN}

Son muchas las décadas, esfuerzos, pasión y recursos dedicados a determinar qué es Patrimonio. Consensuado su valor público, se han puesto en marcha medidas para administrarlo, conservarlo, compartirlo, rentabilizarlo, difundirlo... Quizás haya llegado el momento de variar el eje analítico: detenernos en los sujetos que desde múltiples posiciones y en distintos momentos se sitúan alrededor de ese patrimonio. De ahí surge nuestra inquietud sobre los efectos; sobre qué hace el patrimonio. Buscando respuestas a esta cuestión hemos emprendido un análisis etnográfico en cinco zonas mineras de Andalucía, atendiendo prioritariamente a los procesos de patrimonialización y apropiación patrimonial. Para ello se han tomado como soportes teórico-metodológicos las nociones de intervención social y consumo. El resultado es una aproximación a qué hace el patrimonio, que busca considerar al unísono los efectos vividos en, desde y sobre el mercado, el Estado y la sociedad civil; pero que sobre todo, revela la más estricta dimensión personal que vincula a sujetos y objetos del patrimonio.

Palabras clave: Patrimonialización, Patrimonio minero, Intervención, Consumo, Sujetos.

\section{SUMMARY}

Lots of decades, efforts, passion and resources have been dedicated to determine what is Heritage. Reaching a consensus on its public value, steps have been implemented in order to administrate, conserve, share, promote, difusse it... Maybe the time has come to change the analytic axis: pay attention to the subjetcs which establish themselves around this Heritage from multiple positions and in different moments. There emerges our interest about the effects, about what Heritage does. Looking for answers to that question,

${ }^{1}$ Con este título presentamos parte de los resultados de la investigación "Intervenciones sobre el patrimonio minero en Andalucía: análisis de los procesos de patrimonialización", realizada a lo largo del año de 2004, gracias al auspicio económico de la Dirección General de Bienes Culturales de la Consejería de Cultura de la Junta de Andalucía, dentro de su programa de subvenciones para actividades etnográficas.

RDTP, LX, 2 (2005): 103-127 
we have began an etnographic analysis in five mining zones of Andalusia, focusing as a priority on the heritagization process and heritage appropriation. We have taken as theoretical and methodological tools the notions of intervention and consumption. The result is an approach to what Heritage actually does, trying to consider at the same time the effects in, from and over market, state and civil society; but over all that reveals the strict personal dimension, which links subjetcs and objetcs of Heritage.

Key words: Heritagization, Mining Heritage, Intervention, Consumption, Subjects.

\section{PUNTO DE PARTIDA}

Sentirse inundado por la presencia del patrimonio es una realidad del momento. Ya sea como ciudadano que transita por cualquier calle o ruta del mundo, como profesional que se esfuerza en afinar y rentabilizar el marco de su trabajo, como turista que satisface expectativas de recorrido y descanso, como científico que se acerca y delimita su campo de estudio, nos encontramos con el patrimonio.

Desde su consideración como objeto de reflexión, estudio e inversión, muchas han sido las revisiones que ha tenido la noción de patrimonio. Si repasamos aquella primigenia consideración que lo entendía como legado (que recibimos del padre y que nosotros transmitimos a su vez en aras de la continuidad del linaje), comprobamos cómo ha sido objeto de continuas definiciones en un claro esfuerzo por ampliar esta primera visión de herencia. Se han ido incorporado intereses e inquietudes políticas, económicas o culturales, así como intelectuales-científicas de diversas épocas, que lo han situado, bien al frente de fuertes tendencias regionalistas en busca de la exaltación de valores folclóricos, bien como eje central y justificador de corrientes mucho más próximas a la hermenéutica, preocupadas en señalar el carácter complejo y total de este fenómeno cultural que es el patrimonio (Agudo,1997; Desvallées 1995; García 1998). Diferentes concepciones, que finalmente, y tal como señala André Desvallées (1995: 6-29) para el caso francés, han pasado de la consideración del monumento como soporte de la memoria, al patrimonio como soporte de la identidad.

Sea cual sea el punto teórico de partida, en nuestros días parece existir cierto consenso en considerar al menos dos dimensiones del patrimonio: por un lado la que parte de que todo patrimonio supone una selección de elementos o procesos socialmente significativos (Ballart y Tresseras 2001: 19) y por otro, la que resalta su carácter de bien colectivo, siempre compartido (Limón 1999), y que lo sitúa, en palabras de José Luis García, en el tránsito de la cultura como patrimonio al patrimonio cultural (García 1998). 
De manera casi generalizada se ha alcanzado una consideración teórica de patrimonio como proceso completo en el que se valora y atiende - por todos y cada y uno de los sectores implicados- tanto su definición, como su gestión y difusión. En este sentido, parece que el mayor esfuerzo ha recaído en saber exactamente cuál es el objeto preciso del patrimonio, su delimitación y selección. Acertar a definirlo, buscar sus valores propios, delimitar si es o no identidad, ver si es pasado, legado, herencia.... parecen haber sido las principales incertidumbres a resolver. De este modo, el patrimonio se ha ido convirtiendo en objeto de máximo interés —científico, político, social, económico- ante la posibilidad de completar el círculo de componentes de las todopoderosas nociones de identidad y cultura.

$\mathrm{Y}$ no es que aquí pensemos en el patrimonio como algo ajeno a la cultura, ni mucho menos. Patrimonio es cultura, pues evidentemente nos remite a las formas en que determinados colectivos han resuelto, y siguen resolviendo, sus necesidades y sus adaptaciones culturales, de una manera dinámica, como la cultura, capaz de hacer que en él se reconozcan, de manera diferenciada (del mismo modo en que se participa en la cultura) los diferentes sectores que componen la colectividad. Por eso mismo hemos considerado que quizás ya sea hora de abordar el patrimonio desde otra mirada que contemple de manera más explicita a los sujetos que están envueltos en el patrimonializar. En este camino también se han realizado importantes esfuerzos teóricos y prácticos en busca de una noción de patrimonio que ponga de manifiesto su valor en tanto que construcción social de una realidad concreta (Lenclud 1987; Prat 1997). Aproximaciones que han presentado al patrimonio como algo construido, como un elemento cultural que se ha erigido socialmente (García 1998).

En nuestro trabajo hemos sentido la necesidad de hacer hincapié exactamente en esta idea de proceso, en considerar al patrimonio no solamente como elemento que se ha construido socialmente, sino como algo que —estando en continua definición — "bace sociedad", además de estar construida por ella.

Teóricamente se sabe, se piensa y se defiende al patrimonio como proceso de construcción colectiva. Las formas de apropiación patrimonial y de patrimonialización registradas en nuestra investigación sobre los ámbitos mineros andaluces nos llevan a abordar el patrimonio como algo más complejo que una producción social acabada, establecida y estática, e incluso a cuestionarnos su carácter de "producto", pero sobre todo a preguntarnos por el efecto y alcance que pueden llegar a tener y que tienen estos procesos. Esta es la razón operativa por la que en este trabajo hemos apostado abierta y metodológicamente por utilizar la dimen- 
sión del consumo —en su acepción cultural más amplia, como veremos más adelante- como principal herramienta a la hora de abordar la etnografía de la patrimonialización.

Hemos tenido en cuenta recientes aproximaciones que resaltan precisamente los usos sociales de ese patrimonio (Ariño 2001; Cruces 1998; García Canclini 1999) y que sugieren la oportunidad de girar hacia los procesos y sujetos sociales el ángulo de nuestra mirada: desde el qué es el patrimonio al qué hace el patrimonio. El objetivo no es otro que poder desvelar las posibles y variables relaciones - comunicación- que se establecen entre los sujetos sociales y los objetos patrimoniales. Esta manera de mirar el patrimonio nos lo presenta como una causa, además de como una consecuencia; es decir, el patrimonio no sólo es el resultado de un proceso de intervención, de patrimonialización, es a su vez, en su propio desarrollo, una forma de acción, de generación procesos sociales. La etnografía llevada a cabo en distintas zonas mineras andaluzas pone en evidencia que este patrimonio más que reflejar cosas y situaciones, las provoca.

\section{CONTEXTOS PARA INVESTIGAR QUÉ HACE EL PATRIMONIO}

Estas últimas reflexiones y propuestas, que delimitaremos etnográficamente un poco más adelante, son fruto de nuestro estudio en un particular contexto sociopolítico, cultural y también geográfico: cinco zonas mineras en Andalucía donde, con distintos niveles de planificación y ejecución, se han puesto en marcha procesos de intervención y patrimonialización de la minería. Se trata de comarcas con muchas diferencias, pero también con un elemento común: el cierre de la mina y la crisis social que este acarrea. Esta situación, unida a las políticas de desarrollo y rehabilitación social y/o patrimonial del gobierno autonómico andaluz, convierte casi en necesidad el análisis de los procesos de intervención en materia de patrimonio cultural en nuestra comunidad. Ello es así tanto por el esfuerzo y los recursos dedicados a la rehabilitación e intervención cultural en Andalucía, como por el efecto de esas intervenciones en los procesos de identificación colectiva y de cohesión social. Tampoco podemos olvidar el potencial como recurso económico — vía explotación turística- que presenta el patrimonio minero en particular y el patrimonio cultural en general.

En este contexto sociopolítico y considerando la complejidad-diversidad, tanto de la minería en Andalucía, como de la geografía andaluza, así como de las diferentes políticas de intervención patrimonial en marcha, apostamos por seleccionar para nuestro estudio los casos más rele- 
vantes. Elegimos cinco zonas mineras atendiendo a la importancia y significación desarrollada, a lo largo del tiempo, en el conjunto andaluz, y al diferente sentido y configuración que han tomado los procesos de patrimonialización en cada una de ellas. Concretamente hemos analizado la intervención sobre el patrimonio minero en Riotinto (Huelva), Villanueva del Río y Minas (Sevilla), Linares (Jaén), Alquife (Granada) y Serón (Almería).

En el municipio onubense de Minas de Riotinto se evidencia uno de los procesos más notables de intervención sobre el patrimonio minero en Andalucía y todo el estado español (Ruiz 1998; 1999). Bajo el patrocinio, principalmente, de la Fundación Río Tinto, desde 1987, se han puesto en marcha diferentes acciones encaminadas a la puesta en valor patrimonial de la zona: la apertura del museo minero, la rehabilitación de parte del recorrido del ferrocarril -que en otros tiempos fue el sistema de transporte de la mina y que ahora es uno de los principales reclamos turísticos de la zona-, la visita a zonas urbanas (Barrio Inglés de Bellavista) y arqueológicas (necrópolis romana), así como el diseño de un circuito de visitas a áreas mineras, rematan el paquete turístico ofertado como Parque Minero. Se completa el conjunto de acciones patrimonializadoras con la puesta en funcionamiento del centro de investigación histórica sobre minería y con el reciente inicio por parte de la Junta de Andalucía del trámite para la declaración de la zona minera como Bien de Interés Cultural, con la categoría de sitio histórico ${ }^{2}$.

La confluencia en esta comarca de muchas de las previsibles respuestas a nuestra pregunta inicial sobre qué hace el patrimonio, la fuerte presencia de la cultura minera en la zona, su considerable desarrollo turístico, así como la condensación de políticas patrimonializadoras planificadas, justifica la selección de este contexto de estudio y lo convierte en eje central de nuestro análisis.

Villanueva del Río y Minas (Sevilla) supone un claro exponente de las consecuencias sociales y culturales de la desactivación minera. Las minas de carbón se cierran en 1973, después de haber sido durante mucho tiempo el gran referente de la minería energética en Andalucía y un factor explicativo del desarrollo del ferrocarril en la región. Con este cada vez más lejano pasado, en Villanueva parece tan sólo perdurar un visible - por lo monumental y por su estado de conservación- conjunto de instalaciones minero-industriales en desuso y una sociedad local que plantea problemas de continuidad, tanto en lo material como en lo simbólico. En este caso en concreto, la planificación de acciones y políticas encami-

\footnotetext{
${ }^{2}$ Resolución Dirección General de Bienes Culturales 4 mayo 2004.
} 
nadas a la recuperación patrimonial vienen de la mano de una fuerte preocupación por la reactivación económica y social de su mermada población. A pesar de lo evidente y grave de la situación, pocas han sido las intervenciones - tanto de origen público como privado- sobre el patrimonio en particular y la sociedad local en general. El conjunto de instalaciones mineras ha sido recientemente declarado Bien de Interés Cultural $^{3}$, con posterioridad a una pionera, dilatada y nada clarificadora incoación como Conjunto Histórico ${ }^{4}$, que se inició a mediados de la década de los años ochenta y que supuso el estreno de los órganos autónomos competentes en la materia. En la actualidad y por primera vez, el ayuntamiento de Villanueva plantea, entre sus líneas de actuación prioritarias, la potenciación de este patrimonio minero como protagonista de lo que confían sea su despegue turístico; para ello y al igual que otras muchas zonas mineras andaluzas, se parte del modelo de Parque Minero antes descrito en Riotinto, con la apertura del correspondiente museo, la visita a una explotación de interior, y la rehabilitación del ferrocarril.

La aparición y desarrollo en Villanueva de las asociaciones Munigua y Hueznar — dos de los primeros ejemplos de asociacionismo para la protección y difusión del patrimonio en Andalucía-, unida a la ambigua vinculación de la propia sociedad local respecto a su patrimonio minero, refuerzan la oportunidad de la selección de esta zona para nuestro particular análisis de los procesos de patrimonialización y consumo patrimonial.

Otra de las zonas estudiadas ha sido la ciudad jienense de Linares, en cuyo término municipal, entre finales del siglo XIX y principios del $\mathrm{xx}$, se concentró la minería del plomo en la provincia. A pesar de que el apogeo minero queda bien atrás en el tiempo, la última mina linarense se cerró a principios de los años noventa. No obstante, la presencia de lo minero en el imaginario local se ha visto muy debilitada tradicionalmente. De forma paradójica, una de las razones que nos han llevado a fijarnos en Linares para nuestro estudio ha sido la firmeza con la que lo minero ha pasado recientemente a ocupar un lugar destacado en la agenda política local. La preservación del patrimonio minero se entiende hoy en día como la principal forma de rehabilitación de la cultura minera, y por ende de la identidad local. Esta estrategia se ha convertido en uno de los puntales del debate político y de la intervención patrimonial en Linares.

En el análisis del proceso de patrimonialización minera en Linares tenemos una clara evidencia de cómo la selección, el objeto o la instalación no supone el objetivo final de cualquier intervención patrimonial. En

\footnotetext{
${ }^{3}$ Resolución Dirección General de Bienes Culturales 5 de febrero de 2002.

${ }^{4}$ Resolución Dirección General de Bienes Culturales 7 de abril de 1988.
} 
esta ciudad encontramos uno de los casos más claros de participación de la sociedad civil en la patrimonialización; nos referimos a la presencia y actividades del Colectivo Arrayanes. Este grupo - de una escasa veintena de miembros, pero de gran capacidad de influencia en la política localrepresenta la primera, la más importante $y$, durante muchos años, la única apuesta consistente que ha considerado el patrimonio minero-industrial de Linares como elemento interpretativo y potencial motor de la sociedad local. Su labor central ha consistido en usar el análisis del paisaje minero -en sus múltiples dimensiones - como el gran recurso para el conocimiento y revitalización de la dinámica social en la localidad, antes que como un recurso económico directo. El colectivo, como fuerza viva y activa en la política local, ha participado con su asesoramiento técnico en una de las pocas intervenciones que la administración ha llevado a cabo en Linares: la inscripción en el Catálogo General del Patrimonio Histórico de Andalucía ${ }^{5}$ de diferentes elementos del patrimonio minero. Actualmente participa en el proceso de incoación de otro grupo de cabrias e instalaciones minero-industriales que vendrán a completar el inventario de este patrimonio en la comarca, y paralelamente, trabaja con un protagonismo destacado, en la elaboración de contenidos y la planificación del centro de interpretación de la minería, próximo a inaugurarse en la ciudad. Analizando la trayectoria del Colectivo Arrayanes, y su consideración como fuerza viva local, hemos contemplado su permanente vigilancia e influencia en el conjunto de medidas que la actual corporación municipal ha puesto en marcha en pro de la patrimonialización minera de Linares.

Otro de los lugares elegidos ha sido el municipio granadino de Alquife. Su ubicación a 80 kilómetros de la capital, dentro del contexto agrícola del Marquesado de Zenete, no supone ningún impedimento para afirmar que las minas de hierro de Alquife han constituido un área de gran tradición y profundidad histórica en las labores mineras andaluzas. El reciente cierre de las minas (2000), los problemas derivados de la continuidad de la actividad y de la propiedad de las instalaciones, así como la comparación con otros casos cercanos, han dado pie al debate sobre el patrimonio minero y el desarrollo socioeconómico en la comarca. Asistimos actualmente a los primeros momentos del proceso, donde todo, o mucho, está por hacer en la patrimonialización. Las casi testimoniales iniciativas registradas hasta la fecha evidencian, además de la necesidad de una intervención específica en este patrimonio minero, que estamos

\footnotetext{
5 Resolución Dirección General de Bienes Culturales 3 de diciembre de 2003, y bajo la figura de una genérica colectiva.
} 
en un lugar donde caben todo tipo de iniciativas, tanto privadas como públicas. Una variable nueva a contemplar, al menos explícitamente, dentro de los discursos patrimonializadores objeto de nuestra investigación. Fue precisamente esta situación de incertidumbre "patrimonial" y la amplitud que presenta su futuro, lo que nos animó a seleccionar esta zona como ámbito de estudio y la que otorga un especial interés al análisis de los tiempos, los ámbitos y los protagonistas en torno al patrimonio minero en Alquife.

La provincia de Almería, una de las de mayor tradición minera en Andalucía, conserva innumerables trazos materiales y físicos de la cultura minera. Sobre algunos de ellos se han creado también proyectos de rehabilitación-conservación, como ha sucedido en el coto minero de Las Menas, situado en las cumbres de Los Filabres, dentro del municipio de Serón. En Las Menas se desarrolló una importante etapa de la historia social y económica de la provincia, basada en la explotación de las minas de hierro que se mantuvieron en activo hasta 1968. Desde ese momento las minas caen en una suerte de abandono y desmantelamiento al que se pone fin en 1989, año en que interviene la Consejería de Obras Públicas y Urbanismo de la Junta de Andalucía, mediante el Plan Global de Restauración y Rehabilitación del Poblado de las Menas, con el claro propósito inicial de potenciar actividades culturales, deportivas y de esparcimiento; aunque en realidad lo que se organiza es la puesta en funcionamiento de un apartahotel y un camping en el poblado, aprovechando antiguas edificaciones de las empresas mineras. Ambas instalaciones, a través de un concurso público concluido en el año 2000, pasan a manos de sendas empresas privadas para su explotación turística. Hasta el momento esta iniciativa resume la intervención patrimonial efectiva en la zona.

Este nuevo uso del espacio minero nos obliga a una reflexión sobre su vinculación a la cultura de la que formó parte: sin duda se trata de una estrategia de gran potencial patrimonial y que, al mismo tiempo, puede autofinanciarse, pero ise trata de una actuación sobre el patrimonio minero? ¿O más bien toma como pretexto al patrimonio minero? La explícita puesta en valor turístico del poblado, unida a la aparición y actividades de un cada vez más numeroso grupo de emigrantes del pueblo —que están rehabilitando casas del poblado y que han restituido la celebración en el mes de agosto de la fiesta de Santa Bárbara

\footnotetext{
${ }^{6}$ Emigrantes y descendientes de éstos, residentes casi en su totalidad en Cataluña, que han encontrado en el poblado minero y en la Asociación Santa Bárbara, el lugar para recrear su particular forma de "regreso" a los orígenes. Desde su actual situación social, económica y cultural, se identifican con un espacio recreado al que anclan la
} 
un interesante contexto para nuestra investigación, tanto por su manifiesta vinculación con el desarrollo turístico, como por su particular proceso de apropiación patrimonial con el protagonismo de los emigrantes. Tanto el poblado de Las Menas como el cargadero del ferrocarril Lorca-Baza, ambos en el municipio de Serón, han sido inscritos muy recientemente (2004) en el Catálogo General del Patrimonio Histórico Andaluz, bajo un régimen de protección genérico colectivo $^{7}$, junto a la práctica totalidad de instalaciones mineras de la provincia de Almería. La intervención turística ha precedido a la intervención cultural.

El estudio de estos cinco casos tan diferentes nos ha permitido registrar los elementos y factores relevantes en cada proceso de patrimonialización de manera particular y emprender una posterior comparación entre ellos. Esta doble estrategia ha convertido a la propia conceptualización de la patrimonialización en el rasgo más destacable de la investigación. Más allá de las técnicas utilizadas - por otro lado las esperables en una investigación antropológica-, nuestro objetivo tiene que ver con el análisis de la patrimonialización como proceso cultural en sí mismo. Para ello la apuesta principal es convertir a la patrimonialización en objeto de etnografía, y utilizar dos ópticas teórico-metodológicas convergentes - el consumo y la intervención social- para abordar esa etnografía. No buscamos técnicamente el contenido del patrimonio minero en cada caso para compararlo posteriormente con lo que se ha patrimonializado de hecho, administrativa o turísticamente, sino que hemos (1) rastreado el proceso de conformación de lo patrimonializado, y (2) etnografiado sus pautas y formas preferentes de consumo-producción. En definitiva hemos situado nuestro objeto de atención - el patrimonio minero- en una perspectiva dinámica y en relación a los sujetos. Partimos de una consideración previa que entiende en todo momento a la patrimonialización como intervención social; para ello nos hemos apoyado en la relación que se establece entre los diferentes sujetos y el patrimonio minero, es decir en el consumo.

\section{MEJOR HABLAR DE PATRIMONIALIZACIÓN, INTERVENCIÓN SOCIAL Y CONSUMO PATRIMONIAL}

Analizamos el patrimonio como proceso. Nos interesa la forma en que determinados comportamientos, objetos o ideas se convierten en patrimo-

memoria individual y familiar. La rehabilitación del patrimonio minero (tangible e intangible) es el soporte de esta estrategia de recuperación de la memoria.

7 Resolución Dirección General de Bienes Culturales 7 de enero de 2004 
nio. No nos detendremos en determinar tanto qué sea patrimonio sino cómo se hace ese patrimonio. Desde esta perspectiva, el patrimonio es fruto de una intervención social (Ruiz 2005), por eso sería mejor hablar de patrimonialización.

Como todo proceso, el patrimonio se presenta de forma dinámica construido y en permanente construcción- dentro de un contexto complejo de carácter socio-técnico-político. De aquí que entendamos la patrimonialización como una intervención social que señala y remarca aquello que se entiende como valioso. Nos hemos acercado al análisis de la patrimonialización desde la misma perspectiva con la que se investigan las intervenciones sociales en general (educativas, sanitarias, en los servicios sociales...); a saber: el discurso que subyace en el proceso, las instituciones desde las que se interviene, los técnicos y profesionales protagonistas, y de manera especial en este caso, nos hemos detenido en los posibles efectos de estas acciones. $\mathrm{Y}$ es precisamente aquí, en sus efectos o consecuencias, donde surge la necesidad de contemplar al propio proceso de patrimonialización como generador de espacio y de opinión publica. La etnografía así lo ha reforzado. En Linares, por ejemplo, la patrimonialización de la minería ha adquirido un notable protagonismo en la política local. Polémicas en torno a si las cabrias deben estar en las rotondas de la ciudad o en los contextos mineros originarios, sobre si se debe prestar más atención a la salvaguarda de los restos mineros o a su explotación turística, debates sobre si se debería optar a la declaración como Patrimonio de la Humanidad en virtud de la peculiaridad de ciertas instalaciones mineras..., ilustran ese papel catalizador de las agendas políticas locales que puede desempeñar el patrimonio. Igualmente podemos referir reivindicaciones sobre el uso privado del patrimonio minero en Riotinto, Las Menas y Alquife, o incluso cortapisas al desarrollo patrimonializador desde instancias públicas en Villanueva. En cualquier caso, se demuestra que lo más revelador no estaba en el estudio del patrimonio en sí, sino en el proceso social de acciones y apropiaciones que desde él se genera: esto es, el proceso de patrimonialización.

Todos los contextos etnográficos en los que se ha desarrollado nuestro trabajo están sujetos normativamente a la Ley del Patrimonio Histórico de Andalucía ${ }^{8}$; en ella se establecen los parámetros de cualquier actuación patrimonial dentro de una encrucijada que pretende resolver la articulación entre cultura, patrimonio e identidad andaluza. Por eso, en el desglose de los posibles efectos, y atendiendo a nuestra consideración de la patrimonialización como intervención social, hemos contemplado la

\footnotetext{
${ }^{8}$ Principalmente entre los artículos 61 y 63 del título séptimo.
} 
diversidad de discursos, instituciones y actores que operan sobre el patrimonio minero dentro del eje identidad-cultura; pero sobre todo - siempre pensando en esos agentes- hemos contemplado la oportunidad/necesidad de revisar la propia diversidad de la participación en la cultura e identidad andaluza. De igual manera que sucede en el resto de las identidades, en la andaluza existen multitud de versiones ${ }^{9}$ en las que participar. Por esta razón hemos recurrido a uno de los momentos en que uno/ a manifiesta su voluntad de querer significar — de manera particular- en esa cultura. Patrimonio y cultura son cosas diferentes, pero indudablemente conectadas. Mientras que la cultura es fundamentalmente un recurso analítico, un medio de comprensión, el patrimonio constituye un conjunto de elementos determinados. El patrimonio se construye dentro de la cultura pero al mismo tiempo sirve como forma de representarla, de recrearla. El patrimonio es un producto cultural que al mismo tiempo que representa a la cultura actúa directamente sobre ella. Por eso, frente a la idea de reflejo de la cultura, en nuestros análisis apostamos por el patrimonio minero como factor incidente sobre la cultura. Para ello es necesario detenerse en ese preciso momento en que entramos en relación con el patrimonio minero, que nos otorga la capacidad de ser miembro, de compartir, de entrar en conflicto, de consensuar, de interaccionar ...... para ir, en definitiva, dando forma a lo que Sanmartín denomina semántica cultural (Sanmartín 2004: 169). Por eso recurrimos a la noción de consumo - de consumo patrimonial一, incidiendo en cómo las intervenciones patrimoniales estudiadas no son sólo producto de la sociedad, sino que hacen la sociedad.

Hablar de consumo patrimonial no es más que un intento por ajustar, lo más fácilmente posible, nuestro análisis a la diversidad y el pluralismo propio de la compleja sociedad moderna en la que habitamos. Bajo la dimensión del consumo hemos hallado un espacio de intercambio donde reconocer, en sus acciones, tanto al que elabora el producto como al que acaba consumiéndolo. Poder aplicar las lógicas adscritas a este acto de apropiación desarrolladas por los teóricos del consumo sin duda nos ayudará a entender las consecuencias de ese patrimonio, responder a qué hace el patrimonio minero. Más allá de su conceptualización en disciplinas como la economía o la mercadotecnia, en nuestra investigación el

\footnotetext{
${ }^{9}$ Versiones que conviven, articuladas en relaciones de complementariedad u oposición... "El patrimonio, o mejor dicho, las diversas activaciones de determinados referentes patrimoniales, son representaciones simbólicas de estas versiones de la identidad, ya que ésta, como dice Joan Frigolé no es algo que se lleva dentro y se siente, sino que también se debe expresar públicamenten (Prats 1997: 31).
} 
consumo se presenta como acción social a interpretar; tal y como recuerda García Canclini el consumo sirve para pensar y para hacer ${ }^{10}$ (García Canclini 1991), y hacerlo además de manera diferenciada. De este modo podemos operar a partir de la consideración de consumo como el conjunto de procesos socioculturales en que se realizan la apropiación y los usos de los productos, del tipo que sean.

La primera mañana que compartimos con un grupo la visita y el recorrido trazado en el museo minero de Riotinto fuimos conscientes de la necesidad de analizar, en profundidad y cualitativamente, las cifras de visitantes que amablemente nos habían facilitado. El perfil de visitantes (individuales, escolares, universidades, agencias de viajes, otros) que se establece estadísticamente poco nos servía para reconocer los rostros, comentarios, miradas y emociones recogidas en sucesivas observaciones etnográficas. No nos resultó complicado diferenciar entre los escolares de la comarca que en visita casi obligada al museo confirmaban muchas de las lecciones y leyendas locales con las que iban creciendo; entre los jubilados que tenían en esta visita una actividad más, curiosa si se quiere, dentro de un tour o estancia en la vecina sierra de Aracena; entre un grupo de vecinos del pueblo que acompañaban a familiares venidos de fuera y que mostraban orgullosos la importancia de la minería en la zona; entre antiguos trabajadores de la mina o entre riotinteños emigrados, que nos hacían percatarnos, al transitar por las salas del museo, cómo se hacen llamativos determinados acentos catalanes, vascos o castellanos. Si uno entra en casual conversación o simplemente pone atención indiscreta a las conversaciones que estos visitantes mantienen, es usual escuchar cosas del tipo: "mi padre me contaba...", "mi madre me decía...". En una comarca de tan fuerte tradición migratoria la figura del visitante que busca sus orígenes está siendo cada vez más habitual. La patrimonialización constituye un claro catalizador para este tipo de actitudes, que hemos encontrado también en otras minas, como en Las Menas. No obstante, la capacidad de atracción de la patrimonialización desarrollada en Riotinto, así como el flujo de migraciones que ha tenido como destino o partida esta comarca, la convierten en terreno especialmente abonado del que llamaríamos "turismo de raíces" y que tan vinculado se encuentra a la patrimonialización. En estos casos el consumo patrimonial es especialmente significativo y emotivo. El museo, y el parque minero en general, constituye parte del encuentro que el visitante persigue. Al emocional contraste con una calle, una casa, una dirección referida obsesivamente ("yo me críe en el número 30 de la calle Méndez Núñez"), la plaza de uno de los

${ }^{10}$ El subrayado es nuestro. 
pueblos ("los domingos siempre ibamos al triángulo"), un bar ("en un baile de fin de año en el casino conocí a tu padre"), un comercio ("mis primeros pantalones largos me lo compraron en casa de....), una atmósfera mil veces recreada en relatos de quien ya no está, el museo y su tratamiento científico de la memoria contrapone una visión más serena en la que evocar a través de las fotografías, de algún utensilio, de un nombre propio, de un termino de la jerga minera local (catite, rodo, malacate, contramina...) perdida en la memoria de esos relatos y ahora súbitamente rescatada, de una referencia casual del guía..., en definitiva de algún pretexto que cataliza el recuerdo. Y en ese momento el visitante que busca en la comarca su pasado, el lugareño que evoca espacios tragados por la explotación minera, o el turista ajeno a la cultura minera que busca emociones exóticas, transmiten y comparten relatos, imaginaciones y recreaciones. El museo da soporte a memorias e ilusiones; desde éstas los objetos patrimoniales adquirirán sentidos personales que de nuevo podrán alejarse más o menos de los discursos expositivos oficializados en los textos y recorridos propuestos. El visitante crea una experiencia propia desde el consumo patrimonial.

Comprobar la diversidad de consumos que se produce en este museo nos animó a abordar el análisis de las visitas en sí mismas, no partiendo desde la foto fija a la que invita el discurso museístico y los elementos expuestos, sino desde la polifonía/complejidad que dibuja cada visitante en su comunicación con ese patrimonio. Una relación, un proceso de comunicación, entendida en todo momento como transformación (Hernández 2002: 23), fruto de un intercambio en el que entran en juego todo un conjunto de mediaciones culturales (Barbero 1987) desde las que nos acercamos a cualquier elemento patrimonial, y que marcarán la preferencia, la actitud que mantengamos y el modo en que sintamos ese patrimonio: bien como propio, bien como ajeno. Este proceso de apropiación de nuevo nos traslada al momento en que se produce el encuentro, y nos permite buscar las diferentes razones que subyacen a ese consumo diferenciado. No se trata de gustos y antojos, ni de acciones irreflexivas marcadas únicamente por la eficacia del diseño de un determinado producto (por el discurso museístico y/o patrimonializador), sino de diferentes lógicas reconocibles en la interacción con el patrimonio, y que - tal y como comprobaremos posteriormente-, determinarán en gran medida los ejes en torno a los cuales podemos interpretar los efectos del mismo. En definitiva es una cuestión de lógicas superpuestas. La combinación ${ }^{11}$

\footnotetext{
${ }^{11}$ Atendiendo a las lógicas más relevantes que subyacen a todo acto de consumo (García Canclini 1995; Miller 1999; Ortiz 1998).
} 
de una racionalidad económica que explica el acto por el que se consume un determinado patrimonio, -que nos contextualiza como ciudadanos y nos pone a circular en el mercadomundo-, con otra racionalidad sociopolitica, que sin duda perfila tanto la elección como nuestra pertenencia al grupo, a la sociedad, y que para nada resta intensidad, sino todo lo contrario, refuerza la racionalidad simbólica con la que representamos y exponemos nuestras identificaciones - personal y/o colectiva- ante ese patrimonio, con la que en definitiva nos vamos construyendo como personas.

Dentro de la multiplicidad de acciones e interacciones en las que habitamos, nos presentamos ante el patrimonio como consumidores y sujetos sociales, desarrollando, en nuestra práctica diaria, lo que De Certeau (1999) distingue como estrategias y tácticas expuestas en el uso y/o apropiación de estos elementos patrimoniales, así como en nuestra creatividad cotidiana.

La etnografía del consumo patrimonial nos permite evidenciar, una vez más, la validez del consumo en tanto espacio propicio para comprobar cómo el sentido común no coincide con el buen sentido (García Canclini 1995). Y esta estrategia de investigación no sólo muestra su oportunidad en Riotinto, en el contexto de su museo y parque minero, sino también en contextos donde la patrimonialización y el desarrollo turístico son prácticamente inexistentes, como Alquife ${ }^{12}$. Allí resulta francamente difícil encontrar referencias en torno a las que poder registrar "índices", o mejor indicios, de consumo patrimonial, no quedando muy claro si se trata de una consecuencia de la falta de iniciativas y modelos patrimonializadores, o por el contrario, de la frágil relación entre objetos y sujetos del patrimonio.

En Alquife podemos constatar la utilización de iconografías mineras tanto en el escudo del municipio como en el propio mobiliario urbano, incluso hay un monumento al minero. Otra cosa muy distinta es argumentar que todo ello sea ejemplo del consumo patrimonial tal como venimos refiriéndonos a este. El análisis etnográfico demuestra que el uso de estas imágenes, más que fruto de una particular forma de comunicación y resignificación de la historia y la cultura minera local, es resultado de estrategias de marketing, que difícilmente vuelven a ser utilizadas en

\footnotetext{
12 Todas las descripciones etnográficas están desarrolladas extensamente en la memoria final de la investigación "Intervenciones sobre el patrimonio minero en Andalucía: análisis de los procesos de patrimonialización" aún inédita. Para una profundización en los aspectos generales de dicho proyecto ver Hernández y Ruiz (2005).
} 
cualquiera de las expresiones de lo propio por parte de la sociedad local. Al analizar pormenorizadamente algunas de las acciones sociales relevantes en este municipio, podemos encontrar - a riesgo de forzar nuestro esquema- reacciones y acciones en torno al patrimonio minero, pero sin una manifiesta y clara intencionalidad. Tampoco hemos llegado a constatar actos sociales en los que reconocer esas otras racionalidades (simbólicas, sociopolítica) inherentes al consumo patrimonial que nos hagan patente la relación - comunicación- existente entre los habitantes de este municipio y su patrimonio minero.

En Alquife la reflexión gira en torno a las razones de la inexistencia del consumo patrimonial ¿Porqué parece ser tan difícil la patrimonialización de la minería en el seno de esta sociedad cuando "objetivamente" los recursos patrimoniales son análogos a los de otros casos estudiados? ¿Es que todavía Alquife no ha experimentado la intervención necesaria para desatar maneras de consumo? ¿Es condición sine qua non que se produzca una fase previa de intervención - selección y valoración- sobre el patrimonio para que nos relacionemos con él? ¿De quién esperamos que sea esta intervención?

La escasez de consumo patrimonial - minero- plantea una reflexión en torno a los propios modelos de intervención patrimonial y a las expectativas generadas en torno a estos procesos. Hay que reparar en los elementos que desatan el consumo, y en los posibles sujetos que intervengan en la elaboración del producto a consumir. En Alquife se está manejando una concepción de patrimonio minero ya definido y utilizado en intervenciones realizadas fuera de allí. Se espera que desde el exterior - desde la administración autonómica en este caso, y con instrumentos adecuados con los que custodiar el valor de los bienes- se inventaríen y cataloguen los elementos que componen su propio patrimonio. Fundamentalmente parece ser la valoración y selección externa la que otorga el reconocimiento (saber qué es) del patrimonio, la identificación y valoración del mismo. Una vez establecido lo qué es propio y a la vez valioso, este patrimonio se sentirá como tal, y estará en disposición de ser expuesto ante los demás, de ser promovido, gestionado, publicitado y por ende, consumido. De nuevo podemos estar ante la situación, ya repetida tantas veces en zonas mineras andaluzas, de esperar que vengan de fuera para decirnos lo que tenemos, cual es nuestro valor, cual es nuestro patrimonio; y por tanto inaugurar mediante una intervención social la posibilidad del consumo patrimonial.

Cabe por tanto cuestionarse si será precisamente una intervención patrimonial lo que promueva un consumo patrimonial minero en Alquife, o si al contrario, pase lo que pase en este pueblo, el consumo de este 
patrimonio siempre estará matizado por la vigencia de patrones culturales, apropiaciones y sentimientos de pertenencias previos a la presencia de la mina. Puede que lo minero no haya constituido, todavía, un elemento lo suficientemente aglutinador en torno al cual desatar procesos de autoreconocimiento, de identificación y por ende de patrimonialización, tal y como sí parece haberlo supuesto la ubicación de este municipio dentro de una comarca - geográfica y culturalmente hablando- donde sí han sido determinantes otras actividades agroganaderas, antagónicas a la mina y a la producción industrial (Checa 1995; 1999). No obstante, más de un siglo de actividad minera produce una notable transformación cultural que hace extraño el no reconocimiento en lo minero.

Riotinto y Alquife, cara y cruz del patrimonio minero en Andalucía; casos en apariencia contrapuestos y que un análisis centrado en los procesos de patrimonialización, con la intervención social y el consumo como ejes analíticos, permite desentrañar apropiadamente. Llegados a este punto vimos la oportunidad de aprovechar plenamente los datos que nos ofrecían las distintas etnografías de la patrimonialización, y evidenciar las ventajas compresivas del enfoque que utilizamos. En virtud de los diferentes procesos de patrimonialización y del análisis de las diferentes formas de consumo patrimonial, parecía lógico reflexionar de manera más general sobre las consecuencias del patrimonio minero.

\section{¿QUÉ HACE EL PATRIMONIO?}

Tanto las dimensiones y procesos de la patrimonialización de la minería, como las formas y sentidos que despliegan los sujetos sociales en su relación con el patrimonio minero, nos hacen dirigir nuestra mirada hacia la polifonía y la complejidad. Desde esta perspectiva las cadenas causales se ramifican y bifurcan, se difuminan y capilarizan los efectos y consecuencias, se imbrican los fenómenos y todo se hace recursivo. Inmediatamente nos asaltan las dudas ies útil transitar este tipo de caminos? ¿Nos llevan a alguna parte o más bien nos condenan a vagar en la pura incertidumbre?

Son lugares comunes afirmaciones del tipo "el patrimonio es un fenómeno político", "el principal campo de influencia del patrimonio es el de las identidades", o "el patrimonio es un reflejo de la cultura". En todas ellas se establecen principalmente causalidades de una sola vía, esto es: la política sobre el patrimonio, el patrimonio sobre las identidades, la cultura sobre el patrimonio. Mantenemos que nuestro trabaj: isando nociones como patrimonialización, consumo o intervención social, podrá ayudar a superar esta limitación, y desde ahí transitar vías más anchas, 
de ida y vuelta. Aquí vamos a centrarnos en dos ejes reflexivos ${ }^{13}$ que muestren este cambio de perspectiva.

El primero tiene que ver con el mercado, el Estado y la sociedad civil. Resulta una obviedad que desde todos estos ámbitos se afecta al patrimonio y se condicionan los procesos de patrimonialización, ¿pero igualmente que el patrimonio afecta al mercado, el Estado o la sociedad civil? En las zonas mineras estudiadas hemos detectado con nitidez que el patrimonio, mejor dicho - y sea una muestra de la oportunidad y ventaja del uso de la noción - la patrimonialización, es un claro activador del mercado, del Estado y en su caso de la sociedad civil.

El impacto del patrimonio en el mercado no es ninguna novedad. El análisis de los efectos y valores económicos generados por el patrimonio se ha presentado desde muchas disciplinas como los más evidentes (Greffe 1990). Cómo el patrimonio genera recursos, desarrollo, turismo, actividad económica, etc... parece ser la consecuencia más obvia, visible y cuantificable que produce la patrimonialización. En cambio, sí puede suponer una nueva perspectiva para la dimensión mercantil del patrimonio su efecto, sin prejuicios, sobre el turismo. El sostenido despegue del turismo patrimonial es evidente; una paralela tendencia en el turismo minero es igualmente apreciable no sólo en Riotinto o Las Menas sino en múltiples ejemplos, tanto de España como del resto de Europa (Edwards y Llurdés 1996; Etiembre et al. 1999; Prentice et al. 1998; Pretes 2002; Preite 2000; Thierry 2003). El turismo, a nuestro entender, no sólo es la consecuencia más inmediata y rentable de la acción patrimonial, sino que además supone el camino más "creativo" que surca este patrimonio. El patrimonio minero andaluz ha contribuido a reforzar modestamente la oferta turística de la comunidad autónoma, hasta aquí un efecto "normal". Sin embargo, nuestra investigación pone delante otras vinculaciones entre patrimonio minero y turismo. Se da por asumido que el patrimonio da pie al turismo, que la patrimonialización propicia un posterior desarrollo del turismo. En Las Menas hemos encontrado el proceso contrario. Como señalamos más arriba, la intervención sobre el poblado minero abandonado de Las Menas ha sido básicamente turística (rehabilitación de edificios para aparthotel y camping), ello atrajo a emigrantes y descendientes de los antiguos pobladores del lugar que comenzaron a organizarse e intervenir sobre el patrimonio minero (rehabilitación de edificios, recuperación de fiestas...), ¿podemos decir que el turismo hace posible la patrimonialización? En Las Menas se está asistiendo al proceso de patrimonialización de

\footnotetext{
${ }^{13}$ Ejes de reflexión que presentamos a modo exploratorio, y que en ningún momento consideramos exclusivos o cerrados.
} 
la minería más vital de Andalucía, entendiendo por vital el índice de protagonismo de la sociedad civil; paradójicamente esa intervención patrimonial no sólo es en gran medida ajena al Estado, sino que se activa tras una intervención estatal con un enfoque exclusivamente turístico.

Esta circunstancia constatada en Las Menas nos recuerda que la patrimonialización es principalmente un activador de inversiones, básicamente públicas. El patrimonio en Andalucía, su gestión, protección y difusión (y más escasamente su rehabilitación) activan un porcentaje de presupuestos públicos y privados. Cada vez hay más gente dependiente - en lo económico- no sólo de los resultados generados después de un proceso de selección y puesta en valor de un determinado patrimonio, sino de su planificación, análisis, selección y estudio. La patrimonialización activa la intervención del Estado en las comarcas mineras en crisis, supone un evidente pretexto para una intervención de carácter socio-económico-educativo tan relevante como las escuelas taller, casas de oficio y talleres de empleo, que en las comarcas estudiadas toman casi siempre como ámbitos de actuación la rehabilitación del patrimonio minero. De esta forma prácticamente toda la infraestructura del parque minero de Riotinto ha sido generada desde escuelas taller y similares, igualmente en Linares, y con menor impacto en Villanueva. Estas circunstancias se muestran más claras cuando entendemos conceptualmente que la patrimonialización es una intervención social, una forma más de incidencia sobre el funcionamiento social liderado normalmente por el Estado ${ }^{14}$, y que propicia, tanto un modelo de interpretación de la cultura minera, como una fuente de inversión, empleo y formación. Como vemos, se despliega un impacto integral sobre las sociedades mineras.

Si miramos la patrimonialización de la minería en Andalucía como intervención convergen conceptualmente las inversiones, los empleos, así como el potencial flujo económico que el turismo consiguiente pueda generar. La patrimonialización en las sociedades mineras ( $\tan$ necesitadas de estímulos y transformación) se convierte en un campo de expectativas, proyectos, ilusiones..., y - en tanto que posicionamiento sobre el patrimonio minero- en articulador de procesos de acción social. Desde este momento la patrimonialización da el salto hacia otro ámbito de influencia: la política local.

Una vez más resulta obligatorio (y recomendable) aludir siquiera someramente a la riqueza comparativa de nuestra etnografía. El intenso debate local en torno al uso y orientación que deba darse al patrimonio minero en Linares, las incipientes críticas que van apareciendo en la cmarca de

${ }^{14}$ Ver Cruces (1998:77). 
Riotinto sobre la titularidad privada del patrimonio minero, la polémica en Serón sobre el protagonismo de los emigrantes catalanes en cuanto a la significación del poblado minero de Las Menas, son algunas muestras del papel activador que juega la patrimonialización sobre las distintas arenas sociopolíticas locales. Las formas de poder y de participación social en las comarcas mineras estudiadas se ven afectadas por la patrimonialización. Para ser más explícitos: no se trata sólo de suponer una inserción de lo patrimonial en el sistema político local, sino de que la patrimonialización en sí transforma ese sistema; no sólo se ve afectada políticamente, sino que afecta ella misma a la política local. Empleamos la acepción más amplia de política local, que no la de gobierno local, en el sentido de que no sólo estamos pensando en la capacidad de intervención oficial. En el análisis del patrimonio como intervención -y por supuesto en el de los usos sociales en torno a él generados- está resultando definitoria la participación de la sociedad civil, sobre todo en su forma más extendida de articulación, legitimación y participación, a través de la actividad de asociaciones culturales y de conservación del patrimonio (Ariño 2001). El patrimonio minero en estas localidades está resultando, además de eje motriz en la política local, un activador fundamental de la sociedad civil. Asociaciones en Linares (Colectivo Arrayanes) y Villanueva (Munigua y Hueznar), incluso hermandades con una vocación eminentemente patrimonialista como la Hermandad de Santa Bárbara de Serón, son buena muestra de un nuevo campo asociativo que además ha mostrado un protagonismo clave en el funcionamiento político de las localidades estudiadas. Los procesos de patrimonialización de la minería analizados han mostrado un notable efecto sobre la sociedad civil, máxime cuando las localidades están sumidas en un profundo proceso de crisis interna. En la mayoría de los casos la irrupción de un nuevo tipo de asociacionismo y preocupación política (el patrimonio) ha chocado con la preexistente estructuración sindical y la defensa del empleo minero. Desde esta perspectiva la patrimonialización - como proyecto o como hecho- implica una sustancial reorganización de las formas y contenidos políticos en las comarcas mineras.

Hasta aquí un primer eje de análisis concernido con los ámbitos macro, esto es: el mercado, el Estado y la sociedad civil; con el negocio, las inversiones, la política, las instituciones..., en definitiva los contextos más clásicos de la investigación social. Nuestra apuesta por el consumo como herramienta analítica nos ha emplazado ante otra perspectiva, otro eje de análisis: los sujetos ante el patrimonio. No se trata de un eje independiente, ajeno o desarticulado del anterior. En torno al Estado, el mercado y la sociedad civil se articulan -efectivamente- los sujetos. Pero con 
las herramientas analíticas al uso son invisibles: están como si no estuvieran. Este otro eje de análisis sobre qué hace el patrimonio pretende precisamente visibilizar a los sujetos en el terreno patrimonial. Se parte de la premisa de que el patrimonio desata y canaliza vínculos entre los objetos patrimonializados y los sujetos patrimonializadores.

Considerar el patrimonio, de forma amplia, como vehículo de representación simbólica supone un ámbito específico para sus consecuencias, quizás el menos contemplado por otros estudios o el que menos se materializa en ellos. Esta perspectiva refiere a la parte menos tangible de las sociedades, de los grupos humanos, pero asimismo nos recuerda que todo patrimonio es de alguien, que tiene un sujeto depositario que lo construye, valora, usa y sobre todo consume. Así planteado, el patrimonio se convierte en vehículo de representación y expresión - seleccionado en función de la situación ocupada dentro del grupo y de la propia experiencia personal- de multitud de procesos de autoreconocimiento, sentimientos de pertenencia, de proximidad, lejanía o rechazo... En definitiva, nos permite ver cómo el patrimonio desata procesos para identificarnos con lo que sea, por quien sea, desde donde sea y del modo que sea. En este sentido, y desde la etnografía sobre contextos mineros que nos ocupa, podemos señalar la convivencia de diferentes procesos de identificación dentro del triángulo cultura-patrimonio-identidad. En todos ellos es el patrimonio el que activa los procesos de identificación y de reconocimiento cultural, y ello ocurre tanto a nivel colectivo como individual. Pensamos en identificaciones colectivas, en plural y de manera diversa, intentando hallar un buen lugar para todas y cada unas de las formas de identidad que nos ofrece nuestra sociedad actual ${ }^{15}$. Hemos registrado diferentes plasticidades de esos procesos de identificación en nuestra etnografía, traemos a colación el que consideramos más rico y expresivo.

A priori nada nos hacía presagiar la relevancia de la intervención —urbanística y monumental- en el poblado minero abandonado de Las Menas en el plano simbólico, identificador o reproductor de identidades. Pensábamos en Serón (municipio al que pertenece el poblado minero) tradicionalmente alejado, tanto material, como ideáticamente del mundo minero. Pero la actividad social desarrollada por un grupo de emigrantes catalanes en torno a la Asociación Santa Bárbara pronto nos hizo reflexionar sobre el efecto que el proceso de patrimonialización estaba teniendo sobre este grupo. El que cada año se retorne a este lugar a celebrar, en sentido amplio, que se es de allí, que se tienen elementos - de ese pa-

${ }^{15}$ Refiriéndonos a ese mundo hiperestimulado simbólicamente, y difuminado en sus rituales (Velasco 1989). 
trimonio minero- que se comparten, y con los que se identifican desde su actual condición de emigrantes, sin duda alguna les confiere entidad como grupo. Como grupo, cada vez más formalizado, que cuenta además de con la infraestructura de la asociación (que fundamentalmente los legitima en la sociedad local de Serón para la celebración de las fiestas y que en algunos momentos puede considerarse hasta una excusa), con publicaciones propias y con todo un calendario de actividades que desarrollan en su lugar de residencia habitual —en Cataluña-, lo que en definitiva les sirve para presentarse, tanto ante la sociedad en la que viven -como grupo de emigrantes minero de un pueblo de Almería-, como ante la que les vio partir - como "los catalanes de Las Menas». El soporte de todo ello es Las Menas considerado como recurso patrimonial minero.

Desde este mismo punto de acción podemos analizar la redefinición y reutilización simbólica acaecida después de un proceso de apropiación. Han pasado décadas desde el cese de la actividad minera y han desaparecido las principales rutinas que marcaban la vida social y diaria en las minas, pero es ahora cuando se revitalizan determinadas fiestas y celebraciones en torno a símbolos de ese pasado minero. La celebración de la fiesta en honor a Santa Bárbara en Las Menas, en pleno mes de agosto, en medio de un poblado deshabitado, ocupado por varios centenares de emigrantes residentes en Cataluña que regresan a su pueblo; o la celebración en Villanueva del Río y Minas, en el último domingo del mes de Mayo, de una la romería en honor a la misma santa, con simpecado, fecha, estética y sentido al estilo rociero, ejemplifican ese potencial simbólico y el efecto del patrimonio para los procesos de identificación colectiva en núcleos mineros ${ }^{16}$. Pero no queda todo a un mero nivel colectivo. El efecto personal y familiar de esas recreaciones patrimoniales intangibles se nos ha mostrado con nitidez cuando sus protagonistas establecen un nexo radical entre ese patrimonio y sus estructuras de memoria, los testimonios recogidos son múltiples y todos en el mismo sentido: el contexto patrimonial en cuestión no sólo construye colectivos, sino prioritariamente personas.

La reutilización simbólica de imágenes potenciadas en la patrimonialización - una corta, un castillete, una bocamina...- es una estrategia generalizada en los contextos mineros andaluces (Linares, Riotinto, Villanueva). Se evidencian así las consecuencias del proceso patrimonializador, en el que se utiliza lo minero para significar —las imágenes condesan significados- y construir la sociedad local presente y sobre todo futura.

${ }^{16}$ Un efecto que fácilmente podemos reconocer en otras zonas mineras europeas, como la comarca francesa del Loira (Etiembre et al. 1999). 
Pero pensar en efectos, consecuencias y procesos de pertenencia en torno al patrimonio debe implicar, con la misma intensidad, mirar las identificaciones experimentadas a nivel personal o individual. El patrimonio como campo en el que manifestar (y por ende interpretar) simbólicamente los vinculos creados en los propios procesos de patrimonialización entre sujetos y objetos patrimoniales ha sido uno de nuestros intereses prioritarios. De nuevo los ámbitos de análisis de estos procesos pueden ser múltiples. El más clásico es el de los mayores que se reencuentran con su pasado, circunstancia recurrente en todos los contextos estudiados. Aquí sin embargo referiremos el caso que nos parece más particular, tanto por las generaciones a las que afecta (jóvenes), como por su dimensión temporal (no alude a la recreación de la memoria sino a la construcción del presente social): los alumnos de las escuelas taller que trabajan en la patrimonialización de la minería.

Varios centenares de alumnos han pasado durante la última década por Escuelas Taller de Riotinto o Linares ${ }^{17}$. Hombres y mujeres que además de ser depositarios de ese patrimonio, vecinos de estos pueblos, han contribuido con su trabajo al estado actual con el que se presenta ante los demás el relato de ese pasado: en el museo, edificios rehabilitados, oficios, etc.... Además de ser parte de esa memoria común, entendemos que estos hombres y mujeres han establecido otras formas de relación y vinculación con elementos patrimoniales que evidentemente van más allá de su condición de vecino o residente en esa localidad. En su forma de consumir este patrimonio minero se pueden rastrear racionalidades diferenciadas, que les harán ser y sentir diferentes al relacionarse con elementos comunes. Sobre todo si los comparamos con otras individualidades etnografiadas en nuestro estudio en torno al patrimonio minero en las Menas y más concretamente al desarrollo de campos de trabajo veraniegos, en los que desde hace unos años participan jóvenes no residentes en el municipio. Aquí encontramos alumnos de fuera de la localidad que han residido durante un mes de verano en el poblado minero, participando en labores de restauración y patrimonialización, y que una vez finalizado el período de vacaciones rompen su vinculación con este territorio. Tanto el tiempo vivido en las Menas, como el trabajo concreto realizado en el campo y su conocimiento del patrimonio minero, no dejaran de ser un episodio más de sus vacaciones, un referente exótico antes que cotidiano. Su consumo, su relación y por tanto su uso de este patrimonio minero, sin duda alguna difiere del registrado entre los alumnos

17 Una mayor extensión de este análisis puede encontrarse memoria de investigación anteriormente citada. 
de las escuelas taller antes mencionados, para los que la restauración de tal o cual edificio o infraestructura, significa un hito de su trayectoria vital personal de cara al conjunto de la comunidad. Los alumnos que han construido el museo minero en Riotinto, o restaurado la estación de Madrid en Linares, establecen una vinculación intensa y perdurable (significativa) con un patrimonio del que eran prácticamente ajenos.

Por eso hemos tratado de ir más allá de los procesos de identificación colectiva tradicionalmente adscritos al patrimonio, pensado en su potencial como generador de vínculos individuales paralelos a la propia construcción, reconstrucción, deconstrucción de sujetos, de personas. De esta manera es fácil reconocer a la patrimonialización la capacidad de crear sociedad, de activar formas de pertenencia, de producir emociones..., todo ello en contextos como las comarcas mineras andaluzas, caracterizadas tradicionalmente por una débil cohesión social.

Este último ejemplo, centrado en la relación entre los alumnos de las escuelas taller y el patrimonio minero, enfocado desde una consideración de los procesos de patrimonialización como contextos de intervención social y consumo, nos permitiría sintetizar en un solo referente etnográfico todas las dimensiones de la respuesta a ¿qué hace el patrimonio? De esta forma, lo que aquí presentamos como dos ejes analíticos se diluyen en una espiral que no establece separación alguna entre mercado, Estado, sociedad civil y sujetos.

Visto desde esta perspectiva, una escuela taller que trabaja sobre el patrimonio minero supone: inversiones públicas, decisiones sobre el uso del objeto patrimonial una vez rehabilitado (sede administrativa, espacio de ocio, recurso turístico...), el debate previo en torno a la elección del objeto patrimonial en sí y la discusión más generalizada sobre si enfocar la actuación de la escuela taller sobre el patrimonio minero o sobre otros referentes, las implicaciones en la política local de la rehabilitación del patrimonio minero, la necesaria insistencia ante la administración del Estado para que se conceda a la localidad la escuela taller, el impacto sobre la memoria individual y colectiva local de la rehabilitación del objeto patrimonial seleccionado, por último $-\mathrm{y}$ no por ello menos importante-, la incidencia de la actuación de los jóvenes sobre el objeto patrimonial, lo que los convierte en protagonistas de la rehabilitación del patrimonio. Además, si el objeto en cuestión deviniera en recurso turístico, también cabría considerar la incidencia que la patrimonialización produciría entre los visitantes (iniciados o no, en la cultura minera) y el efecto de la actividad turística sobre la sociedad local. Esta espiral recursiva nos permite una mirada integral sobre qué hace el patrimonio atendiendo a los objetos patrimoniales en sí, a las instituciones, los técnicos, los discursos, las 
relaciones de poder, el negocio, los agentes, las memorias e ilusiones, y sobre todo, a los sujetos que desde múltiples perspectivas confluyen en el patrimonio.

\section{BIBLIOGRAFÍA CITADA}

Agudo Torrico, J. 1997. "Patrimonio Etnológico. Problemática en torno a su definición y objetivos". Boletín P. H. Instituto de Patrimonio Histórico Andaluz. Sevilla: Junta de Andalucía.

Ariño, A. 2001. "Construcción del patrimonio cultural e identidad en la sociedad del riesgo y de la información", en Actas de Congreso de Teoría Sociológica ¿una sociedad de la información? El impacto social de las nuevas tecnologías de la información. Oviedo.

Ballart, J. y T. TResserras. 2001. Gestión del patrimonio cultural. Barcelona: Ariel.

CHECA, F. 1995. Labradores, pastores y mineros en el marquesado de Zenete. Granada: Universidad de Granada y Fundación Machado.

- 1999. "Las minas del Marquesado de Zenete. Demófilo. Revista de Cultura Tradicional 32: 199-239.

CRUCES, F. 1998. "Problemas en torno a la restitución del patrimonio. Una visión desde la antropología". Alteridades 8: 75-84.

De CerteAu, M. 2000. La invención de lo cotidiano. México: Universidad Iberoamericana.

DesvalléES, A. 1995. "Emergente et cheminements du mot patrimoine". Musées et Collections Publiques de France 208: 6-29.

EDWARDS, J. y J. LLURDÉs. 1996. "Mines and quarries. Industrial heritage tourism". Annals of tourism research 23: 341-363.

Etiembre, L; A. Micoud; M. Peroni; A. Peyrache; J. Roux. 1999. Historicité, localité et pratiques de patrimonialisation dans le basin minier de la Loire. Rapport final. París: Mission du patrimoine ethologique. Ministére de la Culture et la Communication.

García Canclini, N. 1991. "El consumo sirve para pensar", en Dia-logos de la Comunicación. Lima: FELAFACS.

- 1995. Consumidores y ciudadanos. México: Grijalbo.

GarCía García, J. L. 1998. "De la cultura como patrimonio al patrimonio cultural". Politica y Sociedad 27.

GREFFE, X. 1990. La valeur économique du patrimoine. La demande et l'offre de monuments. París: Anthropos.

HERNÁNDEZ RAMírEZ, M. 2002. Cultura y Comunicación en Andalucía. Las tecnologías desde el horizonte local. Barcelona: Libros La Frontera.

- y E. Ruiz BALleSteros. 2005. "Intervenciones sobre el patrimonio minero en Andalucía: análisis de los procesos de patrimonialización". Anuario de Etnología Andaluza: $110-123$.

LENCLUD, G. 1987. “La tradition n'est plus ce qu'elle etait". Terrain 9: 110-123.

Limón Delgado, A. 1999. „Patrimonio ¿De quién?", en E. Aguilar (ed.), Patrimonio etnológico. Nuevas perspectivas de estudio. Granada: Instituto Andaluz de Patrimonio Histórico. Consejería de Cultura. Junta de Andalucía. Editorial Comares. 
MARTín Barbero, J. 1987. De los medios a las mediaciones. Comunicación, cultura y begemonia. Barcelona: Ediciones G. Gili.

MILLER, D.1999. Ir de compras: una teoría. México: Siglo XXI.

ORTIZ, R. 1998. Otro territorio. Bogotá: Convenio Andrés Bello.

PRATS, L. 1997. Antropología y patrimonio. Barcelona: Ariel.

PREITE, M. 2000. La gestione museale del patrimonio minerario dismesso. Prato: Editorial.

Prentice, R.; S. WiTt y C. HAMER. 1998. "Tourism as experience. The case of heritage parks". Annals of tourism research 25: 1-24.

PRETES, M. 2002. "Touring mines and mining tourists". Annals of tourism research 29: 439-456.

QUINTERO MORÓN, V. 2005. "El patrimonio inmaterial como instrumento para la interculturalidad ¿una alternativa posible?», en Patrimonio cultural, multiculturalismo $y$ gestión de la diversidad. Sevilla: IAPH, Consejería de Cultura, Junta de Andalucía.

Ruiz Ballesteros, E. 1998. Minería y Poder. Antropología política en Riotinto. Huelva: Diputación de Huelva.

- 1999. "Intervenciones sobre el patrimonio minero en Riotinto: de la identificación colectiva al recurso económicon, en J. Agudo Torrico y E. Fernández de Paz (coords.), Patrimonio cultural y museología: 111-118. Santiago de Compostela: Asociación Galega de Antropoloxía.

- 2005. Intervención social: cultura, discursos y poder. Aportaciones desde la Antropologia. Ciudad: Talasa editores.

SANMARTín, R. 2004. "Mirar aquesta terra: valores culturales e identidad". Revista de Dialectologia y Tradiciones Populares LIX, 2: 161-174.

THIERRY, A. 2003. Tourisme et développement local: Emergence de nouvelles identités a travers de nouveaux territories: Les "Pays". Rapport final. París: Mission du patrimoine ethologique. Ministére de la Culture et la Communication.

Velasco MAILLO, H 1989. "Palabras y rituales, palabras en rituales, palabras rituales" en J. A. Fernández de Rota (comp.), Lengua y cultura. La Coruña: Editorial Castro. 